\title{
Was Sie Krebspatientinnen raten können
}

\author{
Die Vorstellung, durch die Chemotherapie ihre Haare zu verlieren, ist für die meisten \\ Krebspatientinnen geradezu albtraumhaft. Renate Haidinger, ehemals selbst Patientin \\ und heute Vorsitzende von Brustkrebs Deutschland e. V., unterstützt die Frauen mit \\ praktischen Tipps, von der Perückenwahl bis zur Kopfhautpflege.
}

\section{$?$}

Renate Haidinger 1. Vorsitzende Brustkrebs Deutschland e. V., Hohenbrunn b. München; www.brustkrebsdeutschland.de

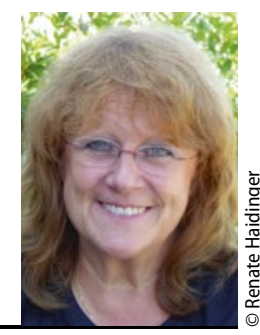

MMW: Der Haarverlust ist vor allem für Frauen subjektiv eine der gravierendsten Nebenwirkungen einer Chemotherapie. Warum ist das so?

Haidinger: Haare gehören für viele Frauen zur Weiblichkeit, und diese wird an einer Stelle beeinflusst, an der es jeder sofort sieht. Sehr oft fallen auch Wimpern und Augenbrauen aus. Ich fand damals allein die Vorstellung, meine Haare zu verlieren, albtraumhaft, trotz aller Beteuerungen der Ärzte, dass sie ja wiederkommen.

\section{MMW: Welche Alltagssituationen} sind besonders schwierig?

Haidinger: Es ist zum einen nicht gerade angenehm, rund um die Uhr mit Perücke herumzulaufen, weil man darunter schwitzt, weil die Kopfhaut juckt etc. Viele Patientinnen wollen sich z. B. vor den Kindern oder dem Partner nicht mit Glatze zeigen. Sie sind dann gezwungen, die Perücke permanent zu tragen. Bei starkem Wind hat man Angst, dass einem das Ding vom Kopf fliegt. Normalerweise kann das nicht passieren, weil die Perücke durch ein Gummi gehalten wird. Aber das Gefühl ist da. Brillenträgerinnen haben zusätzlich das Problem, dass die Bügel hinter den Ohren nicht bedeckt sind. Das sieht dann so nackt aus.

\section{MMW: Wie kann man den Patientin-} nen helfen, den Schock abzumildern, wenn es mit dem Haarausfall losgeht? Haidinger: Zum Beispiel, indem man ihnen rät, in ein Perückenstudio zu gehen, solange sie ihre Haare noch haben. Im Studio kann man dann schon mal verschiedene Modelle ausprobieren. Am schlimmsten fand ich persönlich den Moment, wenn man sich in die Haare greift und alles, was man fasst, in der Hand hat. Die Haare sind dann auf einmal überall: am Boden, auf dem Kopfkissen, im Essen. Daher würde ich raten, sie gleich zu Beginn abzurasieren, damit diese Phase so kurz wie möglich ist.

\section{MMW: Was sollte man bei der Aus- wahl der Perücke beachten?}

Haidinger: Ich persönlich würde eine Kunsthaarperücke bevorzugen, weil die pflegeleicht ist und immer sitzt. Echthaarperücken verhalten sich wie natürliches Haar: bei feuchtem Wetter fangen die Haare an, sich zu kringeln. Viele Frauen suchen sich eine Perücke, die in Farbe und Frisur ihren eigenen Haaren entspricht. Aber es ist auch eine Chance, mal etwas anderes auszuprobieren. Eine junge Krebspatientin hat ein Buch darüber geschrieben, wie sie ihr Aussehen immer wieder komplett verändert hat.*

MMW: Wie soll man nach dem Haarausfall die Kopfhaut pflegen?
Haidinger: Eine Sonnencreme mit hohem Lichtschutzfaktor ist wichtig, weil die Kopfhaut die Sonne ja nicht gewöhnt ist. Bei vielen Frauen juckt die Haut, auch therapiebedingt. Da hilft z. B. das Einreiben mit Olivenöl oder einer sehr fetthaltigen Creme.

Interview: Dr. Elke Oberhofer

- *Sophie van der Stap: „Heute bin ich blond” (Droemer 2008)

\section{Kostenlose Beratung und Broschüre}

Brustkrebs Deutschland e.V. bietet kostenlose Beratung und Informationen rund um das Thema Brustkrebs, speziell zum Thema Haarausfall (kostenlose Hotline: 08000117 112). Die Broschüre „Brustkrebs und Haarverlust" enthält u. a. Tipps zum Binden von Kopftüchern und Schminktipps. Sie kann kostenlos angefordert werden unterinfo@brustkrebsdeutschland.de.

\section{Richtige Pflege der \\ Kopfhaut ist wichtig.}

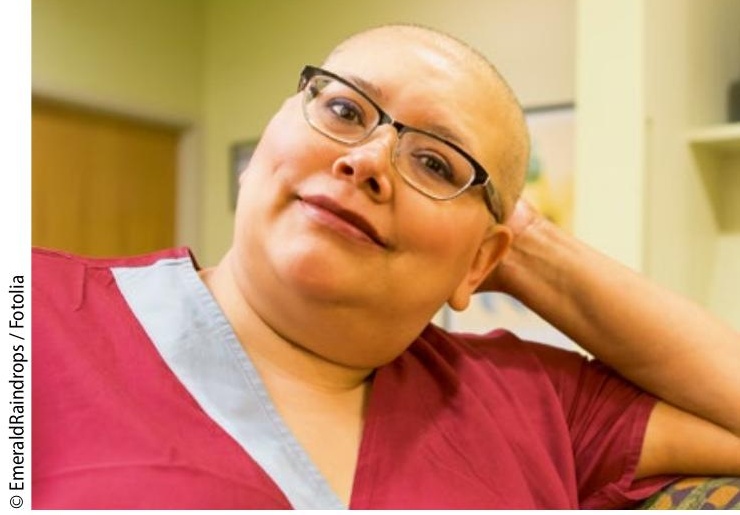

